\title{
Hyperthyroidism causes cardiac dysfunction by mitochondrial impairment and energy depletion
}

\section{Sangeeta Maity, Dipak Kar, Kakali De, Vivek Chander and Arun Bandyopadhyay}

Cell Biology and Physiology Division, CSIR-Indian Institute of Chemical Biology, 4, Raja S. C. Mullick Road, Kolkata 700032, India
Correspondence should be addressed to A Bandyopadhyay Email arunb0925@yahoo.com

\begin{abstract}
This study elucidates the role of metabolic remodeling in cardiac dysfunction induced by hyperthyroidism. Cardiac hypertrophy, structural remodeling, and expression of the genes associated with fatty acid metabolism were examined in rats treated with triiodothyronine $\left(\mathrm{T}_{3}\right)$ alone $(8 \mu \mathrm{g} / 100 \mathrm{~g}$ body weight $(\mathrm{BW})$, i.p. $)$ for 15 days or along with a peroxisome proliferator-activated receptor alpha agonist bezafibrate (Bzf; $30 \mu \mathrm{g} / 100 \mathrm{~g} \mathrm{BW}$, oral) and were found to improve in the Bzf co-treated condition. Ultrastructure of mitochondria was damaged in $\mathrm{T}_{3}$-treated rat heart, which was prevented by Bzf co-administration. Hyperthyroidism-induced oxidative stress, reduction in cytochrome c oxidase activity, and myocardial ATP concentration were also significantly checked by Bzf. Heart function studied at different time points during the course of $T_{3}$ treatment shows an initial improvement and then a gradual but progressive decline with time, which is prevented by Bzf co-treatment. In summary, the results demonstrate that hyperthyroidism inflicts structural and functional damage to mitochondria, leading to energy depletion and cardiac dysfunction.
\end{abstract}

\section{Key Words}

- Thyroid hormone

- Cardiac dysfunction

- Mitochondria

- Fatty acid metabolism

- Energy depletion

\section{Introduction}

Thyroid hormone (TH) is required for normal functioning of nearly all tissues and affects growth, differentiation, metabolism, and oxygen consumption (Yen 2001). The heart is an important target organ of $\mathrm{TH}$ and is very sensitive to minimal changes in serum TH level (Kahaly \& Dillmann 2005). Hyperthyroidism increases cardiac contractility, resting heart rate, lipolysis, blood volume, left ventricular (LV) muscle mass, cardiac output (CO), etc., and decreases vascular tone and afterload (Fadel et al. 2000, Klein \& Ojamaa 2001, Degens et al. 2003, Dillmann 2010). TH supplementation initially improves heart function but chronic hyperthyroidism, if untreated, inflicts detrimental effects to the heart such as hypertrophy, dysfunction ultimately leading to heart failure. Cardiac hypertrophy ensuing hyperthyroidism is due to the hyper-dynamic circulatory system that results from an enhanced metabolic rate, increased blood volume, and decreased peripheral resistance, and all these factors lead to an increased energy demand in the hypertrophied myocardium (Degens et al. 2003).

Cardiac hypertrophy, though initially beneficial for maintaining the $\mathrm{CO}$ under a high workload, is an important predisposing risk factor for cardiac morbidity and mortality (Hunter \& Chien 1999, Shohet et al. 2004). Hypertrophic growth of the myocardium occurs due to an increase in size of the individual cardiomyocytes triggered by many kinds of stimuli such as hypertension, valvular defects, ischemia, myocardial infarction, and neurohormonal factors (Chu et al. 2002, Drazner 2005).

Published by Bioscientifica Ltd 
Under normal conditions, fatty acids are the main source of energy, which undergo $\beta$-oxidation in mitochondria to provide about $70-90 \%$ of total ATP. However, during cardiac hypertrophy, the energy metabolism shifts from fatty acids to glucose, much like the fetal period when mitochondrial content is low (Barger \& Kelly 2000, Garcia \& Goldenthal 2002, Lehman \& Kelly 2002, Goffart et al. 2004). It was demonstrated that metabolic remodeling of cardiomyocytes is one of the important adaptive changes that drive the shift in substrate preference from fatty acids in normal adult heart to glucose in hypertrophy that eventually becomes maladaptive leading to ATP depletion (Ingwall 2009).

A number of important genes involved in fatty acid metabolism (e.g. medium-chain fatty acyl co-A dehydrogenase (Mcad (Acadm)), carnitine palmitoyl transferase-1 beta (Cpt1ß), fatty acid transport protein (Fatp (Slc27a1)), fatty acid translocase (Fat), etc.) are downregulated and expression of peroxisome proliferator-activated receptor alpha (Ppar $\alpha$; Ppara) is also reduced in both rats and humans during cardiac hypertrophy and failure (Barger \& Kelly 2000, Garcia \& Goldenthal 2002, Goffart et al. 2004). Ppar $\alpha$, the transcription factor that belongs to the nuclear receptor superfamily, is the central regulator of mitochondrial fatty acid oxidation (FAO) and is involved in almost every step of FAO in myocardial mitochondria (Barger \& Kelly 2000, Huss \& Kelly 2005). It plays a key role in metabolic remodeling in cardiomyocytes by regulating expression of some of the important genes involved in FAO (Lehman \& Kelly 2002, Goffart et al. 2004, Huss \& Kelly 2004).

Mitochondria are important targets of TH and extensive changes in the mitochondrial compartment take place in response to increased TH levels. Mitochondria biochemically mediate the calorigenic effects of $\mathrm{TH}$ at the cellular level (Goglia et al. 1999). It is known that TH causes a hypermetabolic state resulting in metabolic remodeling in the heart. Although initially TH induces mitochondrial biogenesis, mitochondrial proliferation does not keep pace with the increased energy demand in the hypertrophied heart. Therefore, it is likely that there occurs a mismatch between energy demand and supply in the heart in the hyperthyroid condition (Garcia \& Goldenthal 2002, Degens et al. 2003, Garcia 2010, Sarma et al. 2012). As PPAR $\alpha$ is the central regulator of mitochondrial energy metabolism, it might have a direct role in myocardial bioenergetics imbalance in the hyperthyroid state. In this study, we demonstrate that the PPAR $\alpha$-mediated signaling pathway is crucial in development of LV hypertrophy and that mitochondrial impairment in hyperthyroid rat heart leads to cardiac dysfunction. Furthermore, we show that
PPAR $\alpha$ not only regulates FAO but is also critical for maintaining structural as well as functional integrity of myocardial mitochondria, which in turn is essential for the adequate energy supply needed to maintain the proper functioning of heart.

\section{Materials and methods}

\section{Treatment of animals}

Female Sprague Dawley rats were received from the Institute's animal facility. The animals were handled as per the guidelines of the Institutional Animal Ethics Committee (IAEC) of Indian Institute of Chemical Biology, in accordance with the Committee for the Purpose of Control and Supervision of Experiments on Animals (CPCSEA), Ministry of Social Justice, Government of India. This study was approved by the IAEC. Rats with a body weight (BW) of 180-220 g were randomly assigned to the following treatment groups: control $(n=12)$, triiodothyronine $\left(\mathrm{T}_{3}\right)(n=12), \mathrm{T}_{3}+$ bezafibrate (Bzf) $(n=12)$, and Bzf $(n=8)$. Hyperthyroidism was induced by intraperitoneally injecting the rats daily with $8 \mu \mathrm{g} / 100 \mathrm{~g} \mathrm{BW} \mathrm{T}_{3}$ (Sigma Chemical Co.) for 15 days $\left(\mathrm{T}_{3}\right.$ ) as described earlier (De et al. 2004). To study the progression of cardiac dysfunction induced by hyperthyroidism, rats were also treated with $\mathrm{T}_{3}$ for 2 days $\mathrm{D} 2(n=6), 5$ days D5 $(n=6)$, and 8 days D8 $(n=6)$. The CON group was treated with the same volume of normal saline. To examine the effect of PPAR $\alpha$ agonist in hyperthyroidism-induced cardiac hypertrophy, rats were given Bzf $30 \mu \mathrm{g} / 100 \mathrm{~g}$ BW (MP Biomedicals, Inc., Solan, OH, USA) (Davidoff et al. 2004) in $0.5 \%$ methyl cellulose (MP Biomedicals, Inc.) by oral gavage alone (Bzf) or along with $\mathrm{T}_{3}\left(\mathrm{~T}_{3}+\mathrm{Bzf}\right)$.

\section{Determination of blood pressure}

Noninvasive systolic blood pressure (SBP) of conscious rats was measured by tail cuff method using BIOPAC MP 36 (BIOPAC Systems, Inc., Goleta, CA, USA). The instrument has an animal heating controller (Tail heating $B$ ), small animal tail noninvasive blood pressure system (NIBP 200A), and MP 36 software for data integration.

\section{Estimation of plasma $T_{3}$ and thyroxine concentration}

The concentration of $\mathrm{T}_{3}$ and thyroxine $\left(\mathrm{T}_{4}\right)$ in rat plasma was estimated using Diagnova Eliscan $\mathrm{T}_{3}$ and Diagnova Eliscan $\mathrm{T}_{4}$ (RFCL Ltd., Faridabad, Haryana, India) kits respectively as per the manufacturer's protocol.

Published by Bioscientifica Ltd 


\section{Assessment of cardiac hypertrophy}

The BW of rats was measured and then they were killed by administration of sodium pentobarbital (200 mg/kg BW) intraperitoneally. The hearts were surgically removed and immersed in ice-cold $0.9 \% \mathrm{NaCl}$. Excess blood, atrial tissues, visible fat, and connective tissues were removed. The weight of individual heart was recorded. The tissue samples used for isolation of RNA were immersed in TriPure reagent (Sigma Chemical Co.) and stored at $-80^{\circ} \mathrm{C}$. Samples for biochemical assays were snap frozen in liquid nitrogen and stored at $-80{ }^{\circ} \mathrm{C}$. The degree of hypertrophy was calculated as the ratio of heart weight (HW) to BW (mg/g).

\section{Real-time quantitative RT-PCR analysis}

Expression levels of (Ppar $\alpha)$, atrial natriuretic peptide $(A n p(N p p a))$, brain natriuretic peptide $(B n p(N p p b))$, Cpt1 $\beta$, and Mcad mRNAs were quantified by real-time quantitative RT-PCR using the Dynamo SYBR Green qPCR Kit (Finnzymes, Waltham, MA, USA) and the iCycler realtime detection system and software (Bio-Rad Laboratories). Equal amount (500 ng) of total RNA was used for RT-PCRs. GeneFisher software (http://bibiserv.techfak.uni-bielefeld. de/genefisher/) was used to design sequence-specific PCR primers (Table 1) according to the published gene sequences. The level of expression was calculated as fold change compared to control using the $C t$ value after normalizing with GAPDH. The experiment was repeated with RNA samples from LV tissue from six different rats.

\section{Histological studies}

After 15 days of treatment, hearts were collected and immediately fixed in 10\% formalin and embedded in paraffin following a routine procedure (De et al. 2004). LV sections (5 $\mu \mathrm{m}$ thick) were prepared and stained with hematoxylin-eosin (HE; Sigma Chemical Co.). The stained tissue sections were examined under Olympus BX51microscope (Olympus Corporation) at $400 \times$ magnification and images were captured with a digital camera attached to it. To measure the cross-sectional area $\left(\mu \mathrm{m}^{2}\right)$ of the myocytes, the peripheral margin of 30 myocytes was manually traced and the area was measured using ImageJ software (NIH, Bethesda, MD, USA).

\section{Western blot analysis}

The whole homogenate from LV tissues was prepared as described earlier (Ghosh et al. 2007). Briefly, LV tissue was homogenized in a buffer containing $50 \mathrm{mM}$ Tris- $\mathrm{HCl}$ (pH 7.4), $150 \mathrm{mM} \mathrm{NaCl}, 1 \mathrm{mM}$ each of phenylmethylsulphonyl fluoride and sodium orthovanadate, $1 \mu \mathrm{g} / \mathrm{ml}$ each of pepstatin A, leupeptin, and aprotinin. Protein from mitochondrial fraction was isolated using Mitochondria Isolation Kit for Tissue and Cultured Cells (BioChain Institute, Inc., Hayward, CA, USA) as per the manufacturer's protocol. Equal amounts of protein $(60 \mu \mathrm{g}$ for PPAR $\alpha$ and $40 \mu \mathrm{g}$ for CPT1 $\beta, \mathrm{MCAD}$, prohibitin (PHB), VDAC, and SOD2) was subjected to SDS-PAGE in $10 \%$ polyacrylamide gels. Resolved proteins from gel were transferred to PVDF membranes (Millipore, Billerica, MA, USA) and kept immersed in blocking buffer (10\% nonfat dry milk, $2 \mathrm{mM}$ Tris-base, $13.7 \mathrm{mM} \mathrm{NaCl}, 0.1 \mathrm{M} \mathrm{HCl}$, and $0.1 \%$ Tween 20, $\mathrm{pH}$ 7.6) for $1 \mathrm{~h}$ at room temperature. Then the membrane was incubated overnight at $4{ }^{\circ} \mathrm{C}$ with respective primary antibodies: PPAR $\alpha$ (P0369, Sigma Chemical Co.); MCAD (101730, Cayman Chemical Company, Ann Arbor, MI, USA); CPT1ß (sc-20670), PHB (sc-56467), SOD2 (sc-18503), and actin (sc-1616) (Santa Cruz Biotechnology, Inc.); and VDAC (PC548, Calbiochem, Darmstadt, Germany). Detection of PPAR $\alpha$ and actin was conducted in whole homogenate and mitochondrial fraction was used to examine the expression of other proteins. Pixel density of the bands was quantified using ImageJ software (NIH) from a minimum of three different immunoblots from three different rats in each treatment group.

\section{Electrophoretic mobility shift assay}

An electrophoretic mobility shift assay (EMSA) was performed as described earlier (Cabrero et al. 2002).

Table 1 List of primers used in real-time quantitative RT-PCR

\begin{tabular}{ll} 
Gene & $\begin{array}{l}\text { NCBI GenBank } \\
\text { accession no. }\end{array}$ \\
Anp & NM_012612 \\
Bnp & M25297 \\
Gapdh & XM_216453 \\
Ppar $\alpha$ & NM_013196 \\
Cpt1 $\beta$ & BC085761 \\
Mcad & J02791 \\
\hline
\end{tabular}

\begin{tabular}{l} 
Forward primer $\left(5^{\prime} \rightarrow 3^{\prime}\right)$ \\
\hline GTGTCCAACACAGATCTGATGG \\
TGGGAAGTCCTAGCCAGTCTC \\
GCCATCAACGACCCCTTC \\
CCTGTCCGTCGGGATGTCACAC \\
GCTACACGGAGACAGGACACTG \\
ATGGGTCAGCGGTGCTCTGA
\end{tabular}

\begin{tabular}{l} 
Reverse primer $\left(5^{\prime} \rightarrow 3^{\prime}\right)$ \\
\hline GCCAGCGAGCAGAGCCCTCA \\
GCCGATCCGGTCTATCTTCTG \\
AGCCCCAGCCTTCTCCA \\
GTGACGGTCTCCACGGACATGC \\
TGCCTTTGTCCCGGAAATGAGC \\
TGAAACTCCTTGGTGCTCCACTAG
\end{tabular}


Nuclear proteins from LV tissues of different treatment groups of rats were prepared using Nuclear Extraction Kit (Panomics, Fremont, CA, USA), and the protein concentration was determined using the Bio-Rad DC Protein Assay Reagents (Bio-Rad Laboratories). A double-stranded oligonucleotide containing the PPRE (Huss \& Kelly 2004, Lefebvre et al. 2006) consensus sequence (underlined) sense: 5'-GGAACTAGGTCAAAGGTCATCCCCT-3'; antisense: 5'-CCTTGATCCAGTTTCCAGTAGGA-3' was end labeled with $[\gamma-32 \mathrm{P}]$ ATP using $\mathrm{T}_{4}$ polynucleotide kinase (Fermentas, Inc., Waltham, MA, USA). Labeled probe was cleaned up using the QIAquick Nucleotide Removal Kit (Qiagen) according to the manufacturer's protocol. Nuclear protein $(5 \mu \mathrm{g})$ was incubated with labeled probe for $1 \mathrm{~h}$ at $37^{\circ} \mathrm{C}$. Where indicated, unlabeled oligonucleotide was added before the labeled probe as competitor and incubated for $10 \mathrm{~min}$ on ice. PPAR $\alpha$ antibody (P0369, Sigma Chemical Co.) was added $15 \mathrm{~min}$ before incubation with the labeled probe. Protein-DNA complexes were resolved by electrophoresis at on a $6 \%$ nondenaturing polyacrylamide gel. The protein-DNA complexes were visualized by autoradiography.

\section{Transmission electron microscopy}

For transmission electron microscopy, LV tissue was processed as described earlier (Lewis et al. 2001) with minor changes. Briefly, hearts were dissected out and immediately immersed in ice-cold $0.9 \%$ saline. Excess blood, atrial tissues, visible fat, and connective tissues were removed. A single $2 \mathrm{~mm}$-thick slice was made at the ventricular apex, stored in $2 \%$ glutaraldehyde, and sectioned longitudinally and transversely to generate $1 \mathrm{~mm}$ cubes that were further stored in $2 \%$ glutaraldehyde for $24 \mathrm{~h}$ at $4{ }^{\circ} \mathrm{C}$. Tissues were fixed in $1 \% \mathrm{OsO}_{4}$ in $\mathrm{PBS}$ for $4 \mathrm{~h}$. After fixation, tissues were dehydrated with graded ethanols and embedded in Spurr. Samples were sectioned $(100 \mathrm{~nm})$, stained with uranyl acetate-lead citrate, and examined under a transmission electron microscope (Tecnai $\mathrm{G}^{2}$ Spirit BioTWIN, Czech Republic). For quantification of damaged mitochondria, total number of mitochondria along with the damaged ones was counted in three different micrographs for each treatment group and the percentage of damaged mitochondria was calculated.

\section{Cytochrome $c$ oxidase activity assay}

Mitochondria were isolated from LV tissue of rat using the Mitochondria Isolation Kit for Tissue and Cultured
Cells (Bio Chain Institute, Inc., Hayward, CA, USA). A mitochondria activity assay was done by measuring mitochondria-specific enzyme cytochrome $c$ oxidase activity in isolated mitochondria samples using Mitochondria Activity Assay (Cytochrome $c$ Oxidase Activity Assay) kit (Bio Chain Institute, Inc.) as per the manufacturer's protocol.

\section{ATP assay}

LV tissue homogenate from equal amounts of $\mathrm{LV}$ tissue $(100 \mathrm{mg})$ from different treatment groups was prepared using the Deproteinizing Sample Preparation Kit (BioVision, Mountain View, CA, USA). ATP concentration was measured in the homogenates using ATP Colorimetric/Fluorometric Assay Kit (BioVision) as per the manufacturer's protocol.

\section{Determination of lipid peroxidation}

Lipid peroxides in the cell-free homogenate obtained from LV tissue were determined as described earlier (Ghosh et al. 2007). Briefly, LV tissue ( $200 \mathrm{mg}$ ) was homogenized in ice-cold $0.9 \%$ saline ( $\mathrm{pH} 7.0$ ) with a Potter-Elvehjem glass homogenizer for $30 \mathrm{~s}$. The homogenate was centrifuged at $800 \mathrm{~g}$ for $3 \mathrm{~min}$ at $4{ }^{\circ} \mathrm{C}$ and the cell-free homogenate was mixed with thiobarbituric acid (TBA)-trichloro acetic acid reagent with thorough shaking. After boiling for $15 \mathrm{~min}$, the samples were cooled to room temperature. The absorbance of the pink chromogen present in the clear supernatant obtained after centrifugation was measured at $532 \mathrm{~nm}$ using a u.v.-VIS spectrophotometer (Bio-Rad). The amount of lipid peroxide present in each sample was calculated as the amount of TBA reactive substance (TBARS)/mg protein.

\section{Antioxidant assay}

Blood was collected from rats from different treatment groups and allowed to clot for $30 \mathrm{~min}$ at $25^{\circ} \mathrm{C}$. Then, it was centrifuged at $2000 \boldsymbol{g}$ for $15 \mathrm{~min}$ at $4{ }^{\circ} \mathrm{C}$ and the top yellow layer (serum) was collected. Total antioxidant level including endogenous (enzymes such as SOD, catalase, and glutathione peroxidase; macromolecules such as albumin, ceruloplasmin, and ferritin; and an array of small molecules including $\alpha$-tocopherol, $\beta$-carotene, reduced glutathione, uric acid, and bilirubin) and foodderived antioxidants in different serum samples were determined using the Antioxidant Assay Kit (Cayman Chemical Company) as per the manufacturer's protocol.

Published by Bioscientifica Ltd 


\section{Hemodynamic study}

The rats were anesthetized with sodium pentobarbital (50 mg/kg BW) and heparin (500 units/kg BW). The right internal carotid artery was cranially ligated. A miniaturized conductance catheter (SPR-838 Millar Instruments, Houston, TX, USA) was inserted into the LV through the carotid artery. Stable pressure-volume (PV) loops were obtained under steady-state conditions (Pacher et al. 2008). These PV loops were analyzed using the PVAN 3.5 software (Millar Instruments) to obtain the values of a range of hemodynamic parameters such a heart rate, stroke volume (SV), CO, and so on. The experiment was repeated with six animals in each treatment group.

\section{Statistical analysis}

The data are presented as the mean \pm s.e.m. All the experiments were repeated independently at least with three different animals in each group. The real-time PCR analysis for each gene was repeated with six different rats in each group. Data between two groups were evaluated by Student's $t$-test (independent) and the complete data set among all treatment groups (three or more, as indicated) was evaluated by one-way ANOVA using Microcal Origin 6.0 (Microcal Software, Inc., MA, USA). A level of $P<0.05$ was set as the threshold for statistical significance between the control and various experimental groups.

\section{Results}

\section{Downregulation of PPAR $\alpha$ in hyperthyroid-induced hypertrophied left ventricle}

Development of overt hyperthyroidism was confirmed by determination of plasma $\mathrm{T}_{3}$ level (Table 2 ). There was about a 3.5-fold increase in plasma $\mathrm{T}_{3}$ level after 15 days of $\mathrm{T}_{3}(8 \mu \mathrm{g} / 100 \mathrm{~g} \mathrm{BW})$ treatment compared with vehicletreated control. In Bzf-co-treated rats, plasma $\mathrm{T}_{3}$ level was

Table 2 Plasma levels of thyroid hormones. $n=4$, for control, $T_{3}, T_{3}+B z f$, and Bzf. $T_{4}$ was not detected (ND) in $T_{3}$ and $T_{3}+B z f$ samples. No significant difference was found between plasma $\mathrm{T}_{4}$ levels of control vs Bzf alone

\begin{tabular}{|c|c|c|}
\hline Sample & $\mathbf{T}_{3}(\mathrm{ng} / \mathrm{ml})$ & $\mathbf{T}_{4}(\mu \mathrm{g} / \mathrm{dl})$ \\
\hline Control & $1.36 \pm 0.05$ & $3.48 \pm 0.27$ \\
\hline $\mathrm{T}_{3}$ & $4.66 \pm 0.22$ * & ND \\
\hline $\mathrm{T}_{3}+\mathrm{Bzf}$ & $4.59 \pm 0.19 *$ & ND \\
\hline Bzf & $1.27 \pm 0.04$ & $3.28 \pm 0.11$ \\
\hline
\end{tabular}

$* P<0.01$ vs control.
Table 3 Induction of cardiac hypertrophy by $\mathrm{T}_{3} . n=12$, for control, $\mathrm{T}_{3}$, and $\mathrm{T}_{3}+$ Bzf; $n=8$ for Bzf. No significant difference was found between the parameters of control vs Bzf

\begin{tabular}{|c|c|c|c|}
\hline Sample & HW (mg) & BW (g) & HW/BW $(\mathrm{mg} / \mathrm{g})$ \\
\hline Control & $619.9 \pm 12.7$ & $211.1 \pm 3.39$ & $2.94 \pm 0.03$ \\
\hline $\mathrm{T}_{3}$ & $880.8 \pm 12.6$ & $187.4 \pm 2.24$ & $4.7 \pm 0.06$ \\
\hline $\mathrm{T}_{3}+\mathrm{Bzf}$ & $680.1 \pm 12.3$ & $198.5 \pm 2.0$ & $3.46 \pm 0.05$ \\
\hline Bzf & $616.9 \pm 12.1$ & $204.0 \pm 2.63$ & $3.02 \pm 0.04$ \\
\hline
\end{tabular}

$P<0.01$ (Con vs $T_{3}$ and $T_{3}$ vs $T_{3}+B z f$ ).

found to be almost equal compared with $\mathrm{T}_{3}$-treated rats. Plasma $\mathrm{T}_{4}$ was not detected in $\mathrm{T}_{3}$-treated and $\mathrm{T}_{3^{-}}$and Bzf-co-treated rats. Bzf treatment alone did not significantly change plasma $\mathrm{T}_{3}$ or $\mathrm{T}_{4}$ levels compared with controls. To examine whether PPAR $\alpha$ is involved in hyperthyroidism-induced cardiac hypertrophy, rats were treated with $\mathrm{T}_{3}$ for 15 days in the absence or presence of the PPAR $\alpha$ agonist, Bzf, and cardiac hypertrophy was assessed by measuring $\mathrm{HW}: \mathrm{BW}$ ratio. After 15 days of $\mathrm{T}_{3}$ treatment, HW (combined left and right ventricle) was increased by $\sim 42 \%$ in $\mathrm{T}_{3}$-treated rats compared with control rats (Table 3) leading to about a $60 \%$ increase in HW:BW ratio. Co-treatment of rats with Bzf along with $\mathrm{T}_{3}$ prevented hypertrophy of the heart significantly indicating that PPAR $\alpha$ is involved in cardiac hypertrophy induced by hyperthyroidism. Treatment with Bzf alone did not have a significant effect on either absolute HW or HW:BW ratio (Fig. 1A).

To confirm the induction of cardiac hypertrophy, the expression of molecular markers of hypertrophy, ANP, and BNP was also examined. The level of Anp mRNA was increased over fourfold $(P<0.01)$ compared with control (Fig. 1B), whereas the level of Bnp mRNA was increased about fivefold $(P<0.01)$ after 15 days of $\mathrm{T}_{3}$ treatment (Fig. 1C). Co-treatment of rats with Bzf significantly prevented $\mathrm{T}_{3}$-induced expression of Anp and Bnp in the LV (Fig. 1B and C). Histological examination of HE-stained LV cross-sections also showed the occurrence of myocyte hypertrophy under the hyperthyroid condition that was attenuated by Bzf co-treatment (Fig. 1D and E). Both mRNA and protein levels of PPAR $\alpha$ were significantly reduced in $\mathrm{T}_{3}$-treated rat heart compared with controls, while treatment with Bzf along with $\mathrm{T}_{3}$ enhanced its expression. Bzf alone did not significantly change the expression of Ppar $\alpha$ in the heart (Fig. 2A and B). Taken together, the results demonstrated that PPAR $\alpha$ is involved in the development of pathological cardiac hypertrophy induced by hyperthyroidism.

Published by Bioscientifica Ltd 


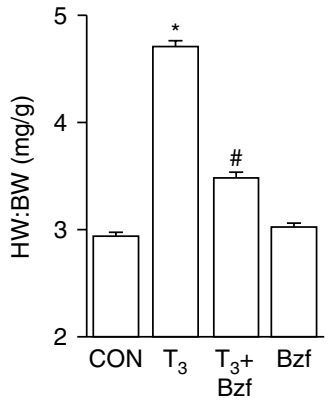

D

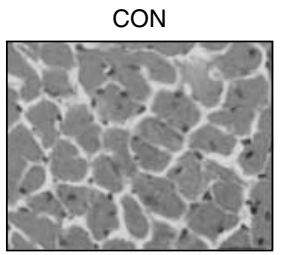

$\mathrm{T}_{3}+\mathrm{Bzf}$

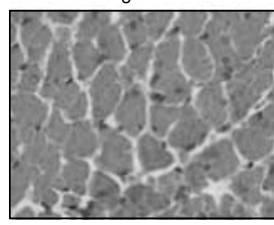

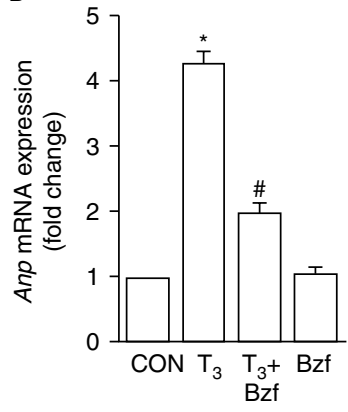

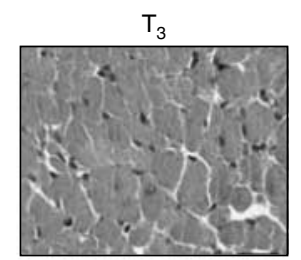

Bzf

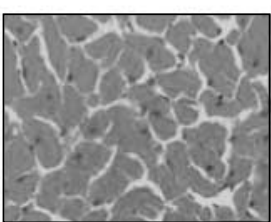

C

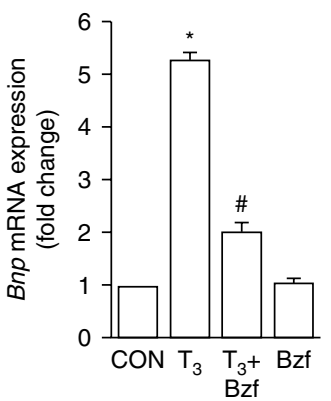

E

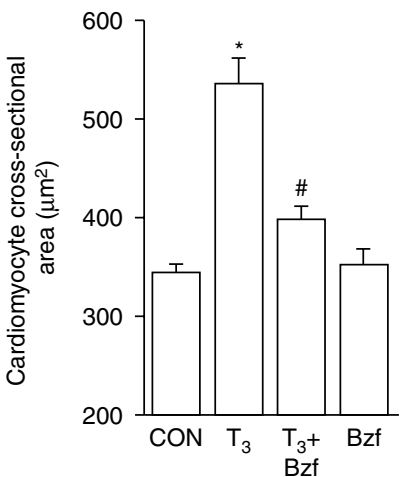

Figure 1

Inhibition of cardiac hypertrophy by Bzf. Separate groups of rats were administered either with vehicle (CON, $n=12)$ or $\mathrm{T}_{3}\left(\mathrm{~T}_{3}, n=12\right)$ or $\mathrm{T}_{3}$ in combination with Bzf ( $\left.\mathrm{T}_{3}+\mathrm{Bzf}, n=12\right)$ or Bzf (Bzf, $\left.n=8\right)$ alone for 15 days and the degree of hypertrophy was expressed as HW to BW ratio in $\mathrm{mg} / \mathrm{g}$ (HW:BW). These data represent mean \pm s.E.M. of HW:BW ratio (A). ${ }^{*} P<0.01$ control vs $\mathrm{T}_{3},{ }^{\#} P<0.01 \mathrm{~T}_{3}$ vs $\mathrm{T}_{3}+$ Bzf. The mRNA expressions of $A n p$ (B) and $B n p(C)$ in the LV were examined by real-time quantitative RT-PCR. ${ }^{*} P<0.01$ control vs $\mathrm{T}_{3},{ }^{\#} P<0.01 \mathrm{~T}_{3}$ vs $\mathrm{T}_{3}+\mathrm{Bzf},(n=6)$ for both (B) and (C) and the complete data set (for $A, B$ and $C$ ) is also significant at $<0.01$ level,

SBP was found to be elevated by $36 \%$ in $\mathrm{T}_{3}$-treated rats compared with controls (Table 4). Co-treatment with the PPAR $\alpha$ agonist Bzf attenuated $\mathrm{T}_{3}$-induced hypertension by about 9\%. Treatment with Bzf alone did not significantly alter blood pressure.

\section{Effect of hyperthyroidism on Ppar $\alpha$ target genes associated with FAO in heart}

As PPAR $\alpha$ was found to be downregulated in LV tissue of $\mathrm{T}_{3}$-treated rats, we examined the expression of two of its important target genes (Cpt1 $\beta$ and $M c a d)$ involved in $\beta$-oxidation of fatty acid after 15 days of $\mathrm{T}_{3}$ treatment. The mRNA as well as protein levels of both CPT1 $\beta$ and MCAD were significantly reduced in $\mathrm{T}_{3}$-treated rat $\mathrm{LV}$ compared with control, which were enhanced when Bzf was co-administered (Fig. 3A, B, C and D). Treatment with Bzf alone did not significantly alter either CPT1 $\beta$ or MCAD expression. analyzed by one-way ANOVA. (D) Representative images (400X magnification) of HE-stained cross-sections through LV of rats belonging to different treatment groups as indicated in figure. Scale bar: $25 \mu \mathrm{m}$. The histogram (E) shows the cardiomyocyte cross-sectional area in $\left(\mu \mathrm{m}^{2}\right)$ measured from 30 randomly selected cardiomyocytes from three different $\mathrm{HE}$-stained sections from three individual rats in each treatment group. ${ }^{*} P<0.01$ control vs $\mathrm{T}_{3},{ }^{\#} P<0.01 \mathrm{~T}_{3}$ vs $\mathrm{T}_{3}+\mathrm{Bzf}(n=3)$. $P$ value for the complete data set is $<0.01$ analyzed by one-way ANOVA. Full colour version of this figure available via http://dx.doi.org/10.1530/JOE-12-0304.

\section{Mitochondrial structural damage in hyperthyroid rat heart}

Expression of the mitochondrial inner membrane protein, $\mathrm{PHB}$, was decreased significantly in $\mathrm{T}_{3}$-treated hearts compared with controls (Fig. 4A). Expression of the outer membrane protein VDAC was also downregulated by $\mathrm{T}_{3}$ treatment (Fig. 4B). Bzf co-administration along with $\mathrm{T}_{3}$ significantly prevented the decrease in expression of both these proteins compared with $\mathrm{T}_{3}$ alone, whereas only Bzf treatment did not show any significant difference in the levels of these two membrane proteins of mitochondria (Fig. 4A and B).

The effect of $\mathrm{T}_{3}$ on the ultrastructure of mitochondria was examined by transmission electron microscopy. As shown in Fig. 4C, the normal architecture of the mitochondria was lost and cristae are damaged in $\mathrm{T}_{3}$-treated rat heart. Also, the ordered distribution pattern of mitochondria in-between the myofibrils was disrupted.

Published by Bioscientifica Ltd 
A

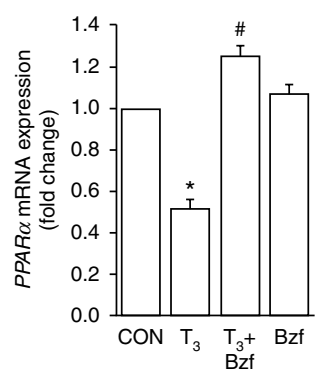

B
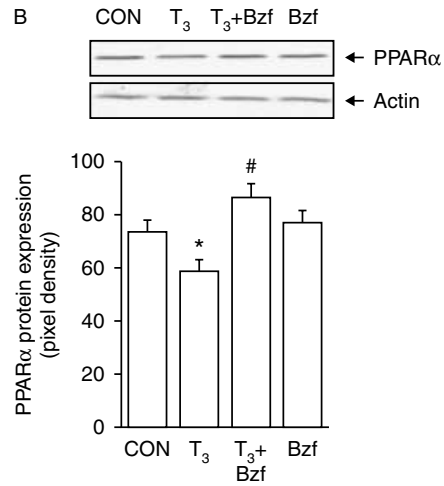

\section{Figure 2}

Downregulation of Ppar $\alpha$ expression in LV tissue. (A) Change in Ppar $\alpha$ mRNA expression in LV of vehicle (CON) or $T_{3}$ treated $\left(T_{3}\right)$ or $T_{3}$ in combination with bezafibrate (Bzf; $\left.T_{3}+B z f\right)$ or Bzf alone for 15 days is shown in the histogram. Each bar represents mean \pm s.E.M. of six rats $(n=6$ in each group). (B) The representative immunoblot showing the level of PPAR $\alpha$ protein in the LV tissue. Each bar in the lower panel shows the mean \pm S.E.M. of pixel intensity of three immunoblots each from different individual rats after normalizing with actin. ${ }^{*} P<0.01$ control vs $\mathrm{T}_{3},{ }^{\#} P<0.01$ $\mathrm{T}_{3}$ vs $\mathrm{T}_{3}+$ Bzf; $n=6$ for $(\mathrm{A})$ and ${ }^{*} P<0.01$ control vs $\mathrm{T}_{3},{ }^{\#} P<0.01 \mathrm{~T}_{3}$ vs $\mathrm{T}_{3}+\mathrm{Bzf}$; $n=3$. No significant difference was seen in control vs Bzf (A and $B$ ).

The overall normal architecture and distribution of mitochondria were preserved when Bzf was co-administered along with $T_{3}$. Treatment with Bzf alone did not detectably affect mitochondrial architecture. The percentage of damaged mitochondria was quantified in the transmission electron micrographs of the abovementioned treatment groups (Fig. 4D). The histogram shows a sharp increase in the number of damaged mitochondria in the hyperthyroid condition compared with control that was prevented by Bzf.

\section{Effect of hyperthyroidism on mitochondrial activity and myocardial ATP level}

Mitochondrial activity, measured as cytochrome $c$ oxidase activity, was found to be reduced in $\mathrm{T}_{3}$-treated LV tissue. ATP level too after an initial increase after 2 days of treatment steadily declined. These two parameters were significantly enhanced upon Bzf co-treatment as shown in Fig. 5A and B. Bzf alone did not have any significant effect on either cytochrome $c$ activity or ATP level.

\section{Oxidative stress in hyperthyroid rat heart by PPAR $\alpha$ downregulation}

As considerable ultrastructural damage and functional impairment of myocardial mitochondria was caused due to $\mathrm{T}_{3}$ treatment, we measured lipid peroxidation as a marker for oxidative stress in LV tissue. As shown in Fig. 6A, a more than twofold increase in lipid peroxidation was observed in $\mathrm{LV}$ of $\mathrm{T}_{3}$-treated rat. Bzf prevented $\mathrm{T}_{3}$-induced elevation in lipid peroxidation. The total antioxidant level in LV was significantly reduced by $\mathrm{T}_{3}$, which was found to be enhanced compared with controls in Bzf-co-treated tissue (Fig. 6B). Bzf alone did not significantly affect lipid peroxidation and total antioxidant level.

\section{Prolonged $T_{3}$ treatment causes cardiac dysfunction via downregulation of PPAR $\alpha$}

Initially, all the hemodynamic parameters were improved significantly by $\mathrm{T}_{3}$ (Table 5 ). However, the SV and diastolic index $(-\mathrm{dP} / \mathrm{dt})$ declined after 5 days. This trend further continued through 8 days and reduced to a minimum level after 15 days, indicating diastolic dysfunction. The marked decrease in SV leads to strikingly reduced CO despite an increased heart rate. After the initial increase, the systolic index $(+\mathrm{dP} / \mathrm{dt})$ also started decreasing, which was prominent after 8 days, indicating a systolic dysfunction. Co-treatment with Bzf prevented the deterioration in hemodynamic parameters resulting in improved cardiac function.

\section{Discussion}

This study demonstrates a possible mechanism of cardiac dysfunction in the hyperthyroid condition involving PPAR $\alpha$-mediated mitochondrial impairment. The molecular basis of hyperthyroidism-induced cardiac malfunction could be attributed to metabolic remodeling and bioenergetic inefficiency of the myocardium due to structural and functional abnormalities of the mitochondria leading to an energy crisis in myocytes. Prevention of hyperthyroidisminduced mitochondrial damage as well as amelioration of hypertrophy by Bzf signifies a pivotal role of the PPAR $\alpha$ pathway in the functioning of the cardiac power house.

A shift from fatty acids to glucose as the main source of energy is known to occur in many models of cardiac

Table 4 Mean \pm s.E.M. of SBP of six animals in each group ( $n=6$ for control, $T_{3}, T_{3}+B z f$, and Bzf)

\begin{tabular}{ll} 
Sample & SBP \\
\cline { 1 - 1 } Control & $112.9 \pm 3.0$ \\
$\mathrm{~T}_{3}$ & $153.7 \pm 1.4$ \\
$\mathrm{~T}_{3}+$ Bzf & $139 \pm 1.0$ \\
Bzf & $110.4 \pm 2.0$ \\
\hline
\end{tabular}

$P<0.01$ (Con vs $T_{3}$ and $T_{3}$ vs $T_{3}+B z f$ ). 
A

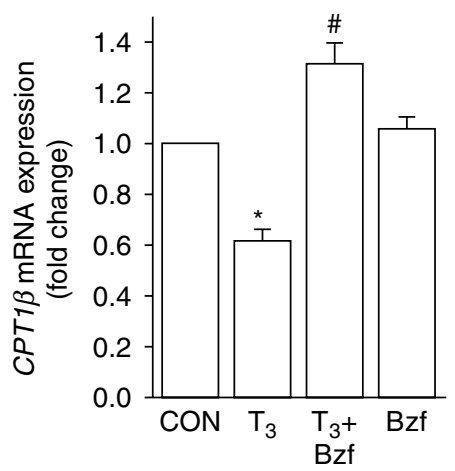

C

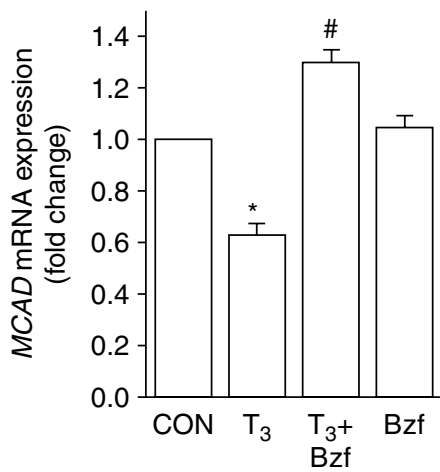

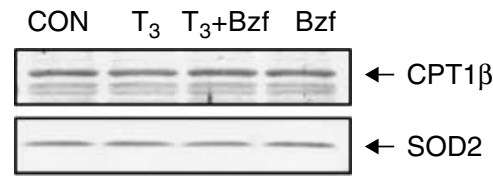

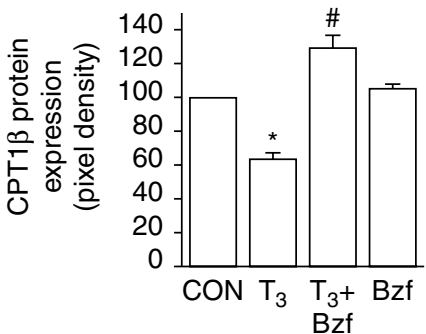

D

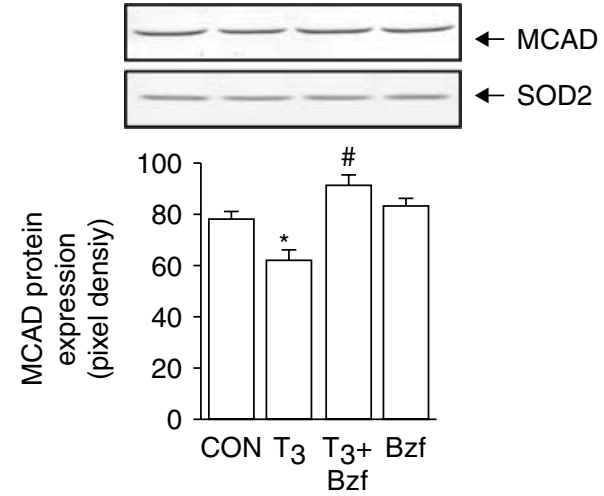

Figure 3

Bzf improves the expression of FAO genes. Expression level of mRNA and protein for CPT1 $\beta$ and MCAD (A, B, C and D) was evaluated by real-time quantitative RT-PCR analysis and western blot analysis, respectively, in LV tissue samples from vehicle (CON) or $T_{3}\left(T_{3}\right)$ or Bzf along with $T_{3}$ or only Bzftreated rats. ${ }^{*} P<0.01$ control vs $\mathrm{T}_{3},{ }^{\#} P<0.01 \mathrm{~T}_{3}$ vs $\mathrm{T}_{3}+\operatorname{Bzf}(n=6)$ (A and $\mathrm{C}$ ). Representative immunoblots ( $B$ and $D)$ show the level of CPT1 $\beta$ and MCAD protein in the mitochondrial fraction of LV tissues. Lower panel shows the

hypertrophy and heart failure (Barger \& Kelly 2000, Garcia \& Goldenthal 2002, Lehman \& Kelly 2002, Goffart et al. 2004, Kieck-Wilk et al. 2005). PPAR $\alpha$ is the central regulator of cardiac fatty acid metabolism (Huss \& Kelly 2004,2005 ) and is found to be downregulated in various models of cardiac hypertrophy (Barger \& Kelly 2000, Garcia \& Goldenthal 2002, Ventura-Clapier et al. 2003, Kieck-Wilk et al. 2005). Consistently, here, we show that downregulation of PPAR $\alpha$ is crucial for myocardial remodeling (Figs 1 and 2) as its agonist Bzf prevented cardiac hypertrophy in the hyperthyroid condition.

Anti-thyroidal effect of fibrates has been reported by previous studies (Rodriguez-Gomez et al. 2008). One of the major mechanisms of fibrates in lowering plasma $T_{3}$ level is by inhibition of deiodinases apart from the induction in uridine diphosphate glucuronosyltransferases average pixel density of three immunoblots from different rats $(n=3)$ after normalizing with SOD2 protein expression. ${ }^{*} P<0.01$ control vs $\mathrm{T}_{3}$ and ${ }^{\#} P<0.01 \mathrm{~T}_{3}$ vs $\mathrm{T}_{3}+\operatorname{Bzf}(n=3)$ for both CPT1 $\beta$ and MCAD proteins. The complete set of data (for $A, B, C$ and $D$ ) are significant at $<0.01$ level (one-way ANOVA). No significant difference was seen in control vs Bzf $(A, B, C$ and $D)$.

(Luci et al. 2006). However, in this study, Bzf co-treatment did not reduce the plasma $\mathrm{T}_{3}$ level (Table 2). This apparent discrepancy might be explained by two facts. First, hyperthyroidism is induced in this study by $\mathrm{T}_{3}$ instead of $\mathrm{T}_{4}$ (Rodriguez-Gomez et al. 2008), and secondly, Bzf is used instead of clofibrate (Rodriguez-Gomez et al. 2008). Despite increased plasma $\mathrm{T}_{3}$ levels, Bzf co-treatment minimally but significantly lowered SBP in our study (Table 4).

Subsequently, Bzf co-administration along with $\mathrm{T}_{3}$ also enhances the expression of the target genes of PPAR $\alpha$ involved in fatty acid transport (CPT1 $\beta$ ) and oxidation (MCAD) compared with the expression levels in control rats (Fig. 3, B, C and D). This is further supported by EMSA, in which the diminished binding of PPAR $\alpha$ protein with its response element in the target gene is seen in the hyperthyroid heart and is enhanced compared with 
A
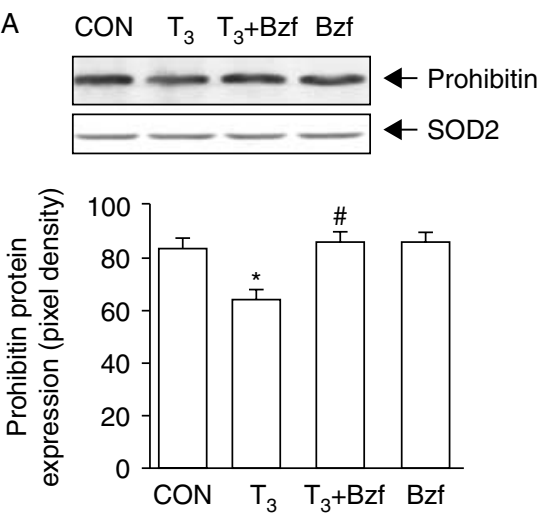

C

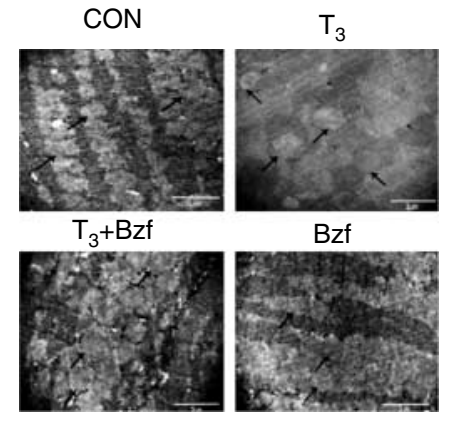

B CON $T_{3} T_{3}+$ Bzf Bzf
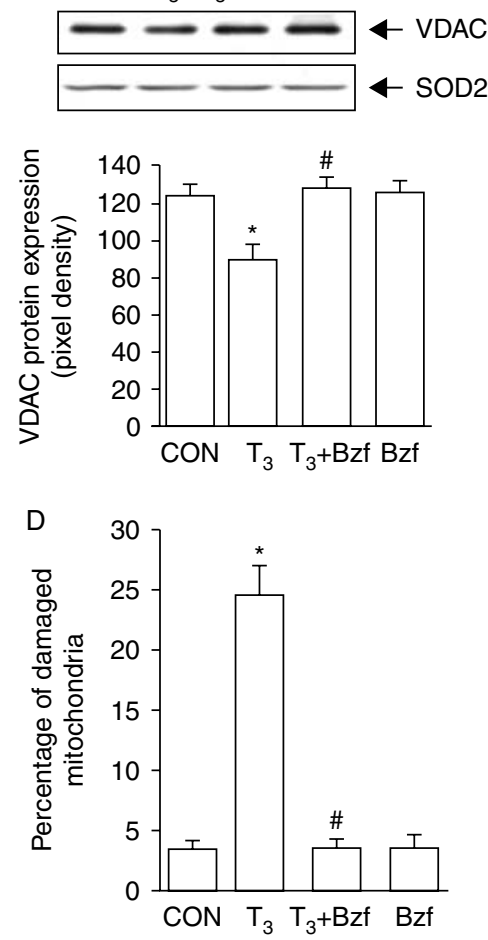

(A and B). Also shown are the representative transmission electron micrographs (C) of LV tissues from similar treatment groups of rats. Arrows point mitochondria in different micrographs, scale bar: $2 \mu \mathrm{m},(n=3)$. The histogram (D) shows the percentage of damaged mitochondria in the micrographs of the above-mentioned treatment groups. ${ }^{*} P<0.01$ control vs $T_{3}$ and ${ }^{\#} P<0.01 \mathrm{~T}_{3}$ vs $\mathrm{T}_{3}+\operatorname{Bzf}(n=3)$. No significant difference from control was found in the number of damaged mitochondria in only Bzf-treated hearts.

might not significantly increase the binding of PPAR $\alpha$ to PPRE and produce any additional detectable effect in the expression of target genes of PPAR $\alpha$ or FAO in the heart.

$\mathrm{TH}$ receptors (TRs) and PPARs interact in various tissues including the heart, and these interactions play an important role in regulating PPAR target gene expression. TRs and PPARs compete for binding with retinoid $\mathrm{X}$ receptor, the common heretrodimerization partner and also to binding sites in the target genes. Several previous studies have shown diminished or enhanced expression of PPAR target genes by TRs (Hyyti \& Portman 2006). In this study, in addition to the decrease in PPAR $\alpha$ expression, TR-PPAR $\alpha$ interaction in the myocardium might be another possible mechanism responsible for the decrease in Ppar $\alpha$ target gene expression.

CPT1 $\beta$ activity is crucial in FAO as it catalyzes the transesterification of long-chain fatty acids, the rate-limiting step in mitochondrial fatty acid uptake. http://joe.endocrinology-journals.org DOI: 10.1530/JOE-12-0304
(C) 2013 Society for Endocrinology Printed in Great Britain 

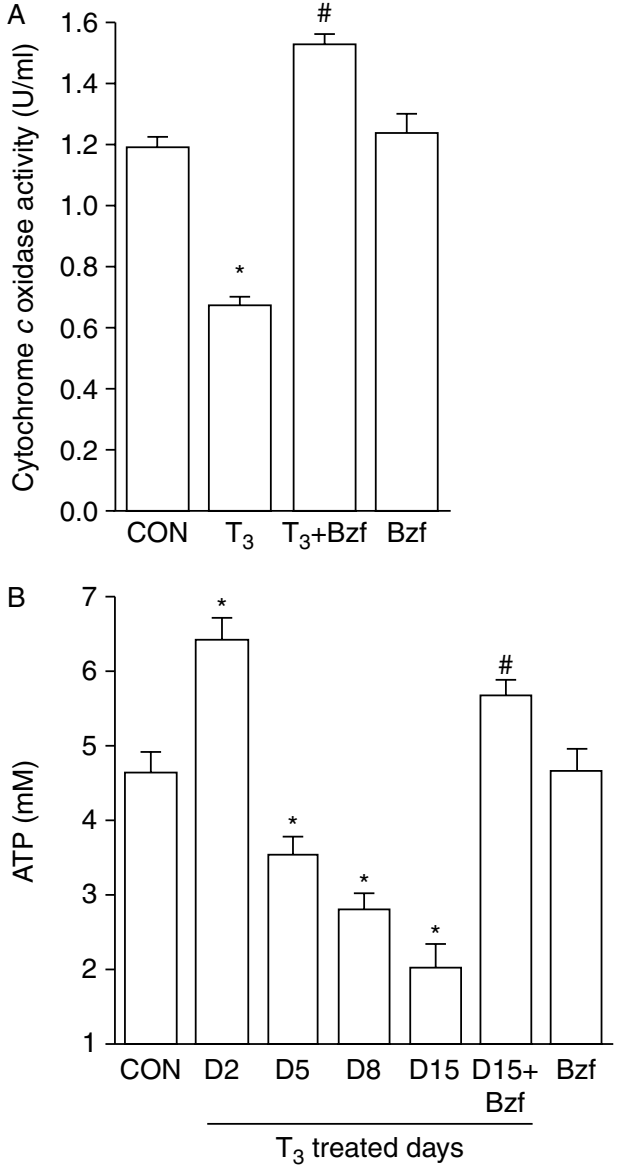

Figure 5

Bzf prevents mitochondrial dysfunction. (A) The histogram represents the mitochondrial activity evaluated by measuring the cytochrome $c$ oxidase activity $(\mathrm{U} / \mathrm{ml})$ in mitochondria isolated from the LV tissues of vehicle (CON) or $T_{3}\left(T_{3}\right)$ or Bzf in combination with $T_{3}$-treated rats $\left(T_{3}+B z f\right)$ or alone (Bzf) for 15 days. Each bar represents mean \pm s.E.M. of five rats $(n=5)$. ${ }^{*} P<0.01$ control vs $T_{3}$ and ${ }^{\#} P<0.01 \mathrm{~T}_{3}$ vs $\mathrm{T}_{3}+$ Bzf. $P$ value for complete data set is $<0.01$, analyzed by one-way ANOVA. Cytochrome $c$ oxidase activity was not significantly different from control in only Bzf-treated LV tissue. (B) The histogram represents the total ATP concentration in homogenate of LV tissue from control (CON), $T_{3}$-treated rats at different time points (viz. 2 days (D2), 5 days (D5), 8 days (D8), and 15 days (D15)) as well as $T_{3}$ along with Bzf for 15 days (D15+Bzf) or only Bzf for 15 days treated rats. Each bar represents ATP concentration as mean \pm s.E.M. from three independent experiments $(n=3)$. ${ }^{*} P<0.01$ control vs $D 2,{ }^{*} P<0.01$ control vs $\mathrm{D} 5,{ }^{*} P<0.01$ control vs $\mathrm{D} 8 * P<0.01$ control vs $\mathrm{D} 15$ and ${ }^{\#} P<0.01 \mathrm{D} 15$ vs D15 + Bzf. No significant difference was found between ATP concentrations of control and only Bzf-treated rats.

MCAD catalyzes the first step in the mitochondrial fatty acid $\beta$-oxidation spiral. Defective expression, function, or mutation in this gene is one of the important causes of in-born errors of metabolism that often lead to childhood cardiomyopathy and sudden death, underscoring the importance of FAO in proper cardiac functioning (Barger \& Kelly 2000, Garcia \& Goldenthal 2002).
Downregulation of these two important target genes of PPAR $\alpha$ in hyperthyroid rat heart might lead to reduced FAO and bioenergetic disorders. Cardiomyocytes have the highest volume density of mitochondria (occupying about 30\% space) in the body and are well organized under the sarcolemma and between the myofilaments so as to maintain efficient diffusion distance. Nearly $90 \%$ of total energy is produced by mitochondrial respiration in the heart and mitochondria are one of the major targets of $\mathrm{T}_{3}$ (Goglia et al. 1999, Ventura-Clapier et al. 2003, Goffart et al. 2004, Huss \& Kelly 2004). In this study, it is interesting to observe that in addition to genes involved with FAO, excess $T_{3}$ in the heart downregulates the mitochondrial membrane proteins $\mathrm{PHB}$ and VDAC (Fig. 4A and B). PHB1 along with its heteromeric partner PHB2 is present in the inner mitochondrial membrane as a macromolecular complex and is known to play a critical role in maintaining normal mitochondrial function and morphology. It acts as a chaperone that stabilizes unassembled membrane proteins and protects newly imported proteins from degradation by m-AAA protease (Coates et al. 2001). Hence, decreased PHB expression in mitochondria might lead to enhanced degradation of membrane proteins and diminished activity of the mitochondrial respiratory chain resulting into increased oxidative stress and loss of mitochondrial membrane potential (Artal-Sanz \& Tavernarakis 2009). VDACs are
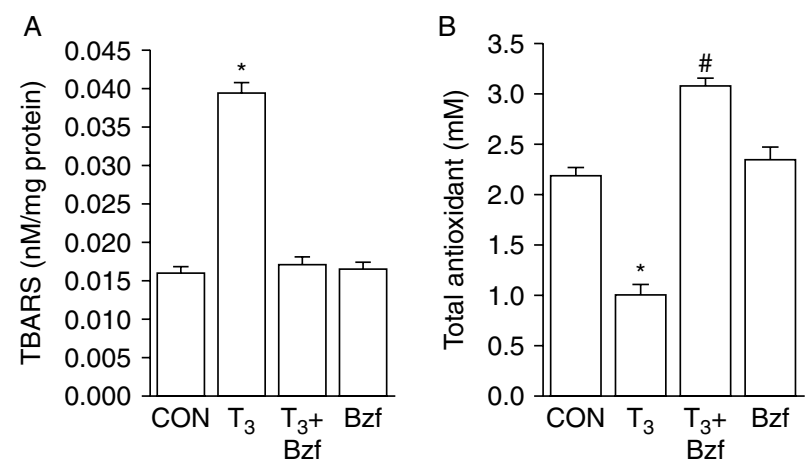

\section{Figure 6}

Bzf prevents oxidative damage in hyperthyroid myocardium. Lipid peroxidation $(A)$ in $\mathrm{LV}$ tissue homogenates from rats treated with either vehicle (CON) or $T_{3}\left(T_{3}\right)$ or Bzf in combination with $T_{3}\left(T_{3}+B z f\right)$ or Bzf alone (Bzf) for 15 days. Each bar in the histogram represents mean \pm s.E.M. of TBARS in $\mathrm{nM} / \mathrm{mg}$ protein estimated from LV tissue of five different animals; $(n=5)$. ${ }^{*} P<0.01$ control vs $\mathrm{T}_{3}$ and ${ }^{\#} P<0.01 \mathrm{~T}_{3}$ vs $\mathrm{T}_{3}+$ Bzf. Total antioxidants (B) present in serum samples of similar groups of rats are shown in the histogram. Each bar represents mean \pm S.E.M. of total antioxidants in three rats; $(n=3) .{ }^{*} P<0.01$ control vs $\mathrm{T}_{3}$ and ${ }^{\#} P<0.01 \mathrm{~T}_{3}$ vs $\mathrm{T}_{3}+$ Bzf. The $P$ value for the complete data set is $<0.01$, analyzed by one-way ANOVA for both (A and B). Lipid peroxidation or total antioxidant level was not significantly different in control vs only Bzf-treated rats.

Published by Bioscientifica Ltd 
Table 5 Effect of $T_{3}$ on heart function. No significant difference was found between the parameters of control vs Bzf (15 days)

\begin{tabular}{|c|c|c|c|c|c|}
\hline \multirow[b]{2}{*}{ Sample } & \multicolumn{5}{|c|}{ Hemodynamic parameters } \\
\hline & Heart rate $(\mathrm{bpm})$ & SV $(\mu \mathrm{l})$ & $+\mathrm{dP} / \mathrm{dt}(\mathrm{mmHg} / \mathrm{s})$ & $-\mathrm{dP} / \mathrm{dt}(\mathrm{mmHg} / \mathrm{s})$ & $\mathrm{CO}(\mu \mathrm{l} / \mathrm{min})$ \\
\hline Control & $363 \pm 6$ & $128 \pm 2$ & $7642 \pm 346$ & $-6266 \pm 210$ & $46352 \pm 326$ \\
\hline $\mathrm{T}_{3}$ (2 days) & $519 \pm 2$ & $149 \pm 2$ & $10245 \pm 185$ & $-8289 \pm 152$ & $77408 \pm 904$ \\
\hline $\mathrm{T}_{3}$ (5 days) & $522 \pm 2$ & $111 \pm 4$ & $9234 \pm 461$ & $-5283 \pm 249$ & $58197 \pm 2758$ \\
\hline $\mathrm{T}_{3}$ (8 days) & $558 \pm 2$ & $58 \pm 1$ & $6763 \pm 125$ & $-3176 \pm 83$ & $32179 \pm 589$ \\
\hline $\mathrm{T}_{3}$ (15 days) & $570 \pm 1$ & $43 \pm 1$ & $4338 \pm 84$ & $-2525 \pm 47$ & $24606 \pm 1005$ \\
\hline $\mathrm{T}_{3}+\mathrm{Bzf}$ (15 days) & $467 \pm 15$ & $131 \pm 3$ & $8798 \pm 398$ & $-6211 \pm 250$ & $61982 \pm 2890$ \\
\hline Bzf (15 days) & $365 \pm 5$ & $126 \pm 2$ & $7432 \pm 343$ & $-6220 \pm 208$ & $46099 \pm 1074$ \\
\hline
\end{tabular}

$n=6, P<0.05$ (for all the parameters of Con. vs $T_{3}$ (2 days), Con. vs $T_{3}$ ( 5 days), Con. vs $T_{3}$ (8 days), Con. vs $T_{3}$ (15 days), and $T_{3}$ ( 15 days) vs $\mathrm{T}_{3}+\mathrm{Bzf}$ (15 days). SV, stroke volume; CO, cardiac output.

ion channel proteins most abundant in the outer mitochondrial membrane. The physiological function of VDACs is to control the movement of adenine nucleotides, $\mathrm{NADH}$, and other metabolites across the outer membrane. ATP produced in mitochondria is available to cytosolic enzymes such as hexokinase, glucokinase, and glycerol kinase via VDAC (Blachy-Dyson \& Forte 2001, Colombini 2004, Shoshan-Barmatz et al. 2010). Therefore, reduced expression of VDAC might adversely affect various metabolic pathways, resulting into insufficient energy production in cardiomyocytes in the hyperthyroid condition. The loss of mitochondrial cristae density and cristae damage (Fig. 4C) leads to the disruption of the respiratory chain complex (Abel \& Doenst 2011). This could be the cause of reduced cytochrome $c$ oxidase enzyme activity (Fig. 5A) and diminished ATP concentrations (Fig. 5B) rendering the hypertrophied heart energy deficient (van Bilsen et al. 2009, Tsutsui et al. 2009). Phosphocreatine (PCr) serves as the primary energy reserve in the heart and the phosphoryl group from it is transferred to ADP for resynthesis of ATP that is used for muscle contraction. This reaction is catalyzed by creatine kinase (CK). The CK system plays an important role under stressed conditions such as hypoxia and ischemia by transferring the phosphoryl group to ADP from PCr and slowing the rate of ATP depletion. It also helps myocytes to sustain increased workload under stressed conditions (Liao et al. 1996). A decrease in PCr along with ATP content in the heart has been reported in LV hypertrophy and failing myocardium in earlier studies (Liao et al. 1996, Pinz et al. 2011). Mitochondrial enzyme activity and ATP levels have also been reported to be decreased in pacing induced heart failure (Marín-García et al. 2001). Consistently, our study demonstrates ATP depletion in the heart under the hyperthyroid condition and is probably accompanied by depletion in PCr level and/or CK activity. Also, the initial increase in ATP concentration during $\mathrm{T}_{3}$ treatment might partly be attributed to $\mathrm{PCr}$ along with oxidative phosphorylation in the myocardium to sustain enhanced workload.

Lower myocardial energy production indicates reduced oxygen consumption and limits cardiac work under high workload conditions. The disorganized distribution and diminished ratio of mitochondria to myofibrils would further diminish the effective diffusion of ATP from mitochondria to myofibrils and would adversely affect cardiac function (Ventura-Clapier et al. 2003).

Mitochondria produces a major part of reactive oxygen species (ROS) in cell as a byproduct of the electron transport chain, which is detoxified by the cellular antioxidant system under physiological conditions (Gustafsson \& Gottlieb 2008, Zhang et al. 2008). Excess $\mathrm{T}_{3}$ induces a hypermetabolic state in the heart and also increases cellular respiration leading to increased ROS production, which is not completely neutralized by the cellular antioxidants, and there is gradual and progressive accumulation of ROS in cardiomyocytes (Ghosh et al. 2007, Abel \& Doenst 2011). This is evident from increased lipid peroxidation and depletion of cellular antioxidants seen after 15 days of $\mathrm{T}_{3}$ treatment (Fig. $6 \mathrm{~A}$ and $\mathrm{B}$ ). The level of antioxidants is increased compared with control when Bzf is co-administered along with $\mathrm{T}_{3}$ (Fig. 6B). This indicates that the increased amounts of antioxidants are required to neutralize the increased ROS generated due to higher metabolic rates and hence we see no net increase in lipid peroxidation. Mitochondrial ROS also leads to opening of the mitochondrial permeability transition pore (Garcia \& Goldenthal 2002, Gustafsson \& Gottlieb 2008, Abel \& Doenst 2011), resulting in loss of proton gradient and electrical potential across the inner mitochondrial membrane. This may lead to uncoupling of

Published by Bioscientifica Ltd. 
oxidative phosphorylation, influx of water to cause mitochondrial swelling, cristae remodeling, and rupture of outer membrane (Gustafsson \& Gottlieb 2008). Excessive ROS generation has been linked to transition from compensatory to decompensatory hypertrophy and eventually to heart failure (Gustafsson \& Gottlieb 2008, Tsutsui et al. 2009, Abel \& Doenst 2011).

$\mathrm{TH}$ is known to enhance force and speed of systolic contraction and speed of diastolic relaxation through upregulation of sercoplasmic reticulum $\mathrm{Ca}^{2+}$ ATPase-2 (Serca2 (Atp2a2)) transcription and downregulation of phospholamban in cardiomyocytes (Klein \& Ojamaa 2001, Kahaly \& Dillmann 2005). Heart rate (chronotropy) and $\mathrm{CO}$ also increases due to hyperthyroidism. Increased Serca2 expression increases the speed of diastole by increasing the rate of $\mathrm{Ca}^{2+}$ reuptake by the sarcoplasmic reticulum, consuming ATP in the process (Klein \& Ojamaa 2001, Yen 2001, Kahaly \& Dillmann 2005, Dillmann 2010). Consistently, our findings show an initial increase in heart rate, SV, and systolic and diastolic indexes, leading to greater CO (Table 5). The increase in SERCA2 expression increases cardiac energy demand. The concomitant ATP depletion in the hypertrophied heart would adversely affect the efficacy of the SERCA pump, compromising the rate of $\mathrm{Ca}^{2+}$ reuptake and conequently prolonging $\mathrm{Ca}^{2+}$ transient. This would result into impaired diastolic function of the heart, diminishing the beneficial effect of increased SERCA2 expression and might trigger ventricular fibrillation (Braunwald \& Bistrow 2000, Yen 2001, Ashrafian et al. 2003, Ingwall \& Weiss 2004, Kenzel et al. 2008, Pinz et al. 2011). Consistently, our findings from the hemodynamic analysis show a gradual decrease in diastolic index $(-\mathrm{dP} / \mathrm{dt})$ (Table 5). With progression of pathological hypertrophy, impaired diastole would lead to progressive decreases in sarcomeric length/stretch resulting in lesser force generation during systole (Ashrafian et al. 2003). This would progressively diminish the efficiency of the cardiac pump reflected in the significant decrease in $\mathrm{SV}$ that is evident after 5 days of $\mathrm{T}_{3}$ treatment. The decline in $\mathrm{SV}$ is so pronounced after 8 days of $\mathrm{T}_{3}$ treatment that even an increased heart rate is unable to prevent the decrease in $\mathrm{CO}$, which reaches a remarkably minimum level after 15 days of treatment. Decline in systolic index $(+\mathrm{dP} / \mathrm{dt})$ after 8 days of treatment is also evident and significantly contributes to the decrease in SV and CO. Our data reveal that cotreatment with Bzf improves the cardiac function and the parameters lie within the range of 2 days and 5 days of $\mathrm{T}_{3}$ treatment. This indicates that probably this is the transition period of adaptive to maladaptive hypertrophy and Bzf intervenes during this period to prevent the progressive decline in functional parameters.

Another probable contributor responsible for reduced force generation could be the increase in myosin heavychain alpha $(\mathrm{MHC} \alpha)$ in hyperthyroid heart, which has a higher ATPase activity and increased velocity of contraction than MHCß (Klein \& Ojamaa 2001, Yen 2001, Ashrafian et al. 2003). The resultant hyper-contractility coupled with increased heart rate and decreased sarcomeric length due to impaired diastolic function could lead to increased crossbridge detachment and premature ventricular beats even before the contraction is complete without contributing to force generation, consuming ATP in the process. Thus, enhanced contractility seen during the initial stage of treatment $T_{3}$ would result in reduced mechanical efficiency and increased energy cost for force generation (Ashrafian et al. 2003, Kenzel et al. 2008). Consistently, our data show that though enhanced systolic index $(+\mathrm{dP} / \mathrm{dt})$ is seen even after 5 days of $\mathrm{T}_{3}$ treatment, the trend of decline in $\mathrm{CO}$ is apparent at this stage with a significant decrease in diastolic index $(-\mathrm{dP} / \mathrm{dt})$, which might be the reason for the decrease in $\mathrm{CO}$ and SV. This continuum of hemodynamic events suggests that probably diastolic dysfunction paves the way for systolic abnormalities in hyperthyroidism-induced cardiac hypertrophy.

Bzf has been reported to reduce heart rate and blood pressure in hypertriglyceridemic patients, and these changes are likely to be caused by Bzf-mediated improvement of endothelial function (Jonkers et al. 2001). It is possible that NO-mediated induction of the parasympathetic nervous system might be involved in Bzf-mediated heart rate reduction in this study. However, further studies are warranted to unveil this mechanism.

In summary, $\mathrm{TH}$ has distinct effects on nuclei and mitochondria. Prolonged TH administration downregulates nuclear encoded genes involved in $\beta$-oxidation of fatty acid, the major energy-generating pathway in cardiomyocytes, by reducing the expression of the central transcription factor for these enzymes, PPAR $\alpha$. Hyperthyroidism also reduces expression of mitochondrial membrane proteins causing structural damage and functional impairment of mitochondria, leading to reduced ATP generation, rendering the hypertrophied heart energy starved. ROS generation is also enhanced in the hyperthyroid condition that leads to cardiac dysfunction. Downregulation of PPAR $\alpha$ might be contributing to enhanced ROS generation as its agonist could successfully attenuate ROS levels. Therefore, PPAR $\alpha$ agonists might act as cardio-protective agents by preventing mitochondrial dysfunction in addition to their lipid-lowering actions.

Published by Bioscientifica Ltd. 
Bzf, used in this study as PPAR $\alpha$ agonist, may also activate $\operatorname{PPAR} \beta / \delta$ and $\operatorname{PPAR} \gamma$. As $\operatorname{PPAR} \beta / \delta$ is expressed in comparable amounts along with PPAR $\alpha$ in the adult heart and is said to influence FAO, the effects of Bzf might partly be attributed to PPAR $\beta / \delta$.

\section{Supplementary data}

This is linked to the online version of the paper at http://dx.doi.org/10.1530/ JOE-12-0304.

\section{Declaration of interest}

The authors declare that there is no conflict of interest that could be perceived as prejudicing the impartiality of the research reported.

\section{Funding}

This work was supported by the Council of Scientific and Industrial Research (CSIR), New Delhi, India (grant number: SIP 007) and BSC 0206.

\section{Acknowledgements}

The authors acknowledge Priyam Banerjee for technical support in manuscript preparation. They are grateful to Dr Sanmoy Karmakar, Jadavpur University, Kolkata, for providing facilities for measurement of noninvasive blood pressure in rat.

\section{References}

Abel ED \& Doenst T 2011 Mitochondrial adaptations to physiological vs. pathological cardiac hypertrophy. Cardiovascular Research 90 234-242. (doi:10.1093/cvr/cvr015)

Artal-Sanz M \& Tavernarakis N 2009 Prohibitin and mitochondrial biology. Trends in Endocrinology and Metabolism 20 394-401. (doi:10.1016/j.tem. 2009.04.004)

Ashrafian H, Redwood C, Blair E \& Watkins H 2003 Hypertrophic cardiomyopathy: a paradigm for myocardial energy depletion. Trends in Genetics 19 263-268. (doi:10.1016/S0168-9525(03)00081-7)

Barger PM \& Kelly DP 2000 PPAR signaling in the control of cardiac energy metabolism. Trends in Cardiovascular Medicine 10 238-245. (doi:10.1016/S1050-1738(00)00077-3)

van Bilsen M, van Nieuwenhoven FA \& van der Vusse GJ 2009 Metabolic remodeling of the heart: beneficial or detrimental? Cardiovascular Research 81 420-428. (doi:10.1093/cvr/cvn282)

Blachy-Dyson E \& Forte M 2001 VDAC channels. IUBMB Life 52 113-118. (doi:10.1080/15216540152845902)

Braunwald E \& Bistrow MR 2000 Congestive heart failure: fifty years of progress. Circulation 102 IV-14-IV-23. (doi:10.1161/01.CIR.102. suppl_4.IV-14)

Cabrero A, Alegret M, Sanchez RM, Adzet T, Laguna JC \& Carrera MV 2002 Increased reactive oxygen species production down-regulates peroxisome proliferator-activated pathway in C2C12 skeletal muscle cells. Journal of Biological Chemistry 277 10100-10107. (doi:10.1074/jbc. M110321200)

Chu G, Haghigh K \& Kranias EG 2002 From mouse to man: understanding heart failure through genetically altered mouse models. Journal of Cardiac Failure 8 S432-S449. (doi:10.1054/jcaf.2002.129284)

http://joe.endocrinology-journals.org DOI: $10.1530 /$ JOE-12-0304
(C) 2013 Society for Endocrinology Printed in Great Britain
Coates PJ, Nenutil R, MMcGregor A, Picksley SM, Crouch DH, Hall PA \& Wright EG 2001 Mammalian prohibitin proteins respond to mitochondrial stress and decrease during cellular senescence. Experimental Cell Research 265 262-273. (doi:10.1006/excr.2001.5166)

Colombini M 2004 VDAC: the channel at the interface between mitochondria and the cytosol. Molecular and Cellular Biochemistry 256/257 107-115. (doi:10.1023/B:MCBI.0000009862.17396.8d)

Davidoff AJ, Mason MM, Davidson MB, Carmody MW, Hintz KK, Wold LE, Podolin DA \& Ren J 2004 Sucrose-induced cardiomyocyte dysfunction is both preventable and reversible with clinically relevant treatments. American Journal of Physiology. Endocrinology and Metabolism 286 718-724. (doi:10.1152/ajpendo.00358.2003)

De K, Ghosh G, Datta M, Konar A, Bandyopadhyay J, Bandyopadhyay D, Bhattacharya S \& Bandyopadhyay A 2004 Analysis of differentially expressed genes in hyperthyroid-induced hypertrophied heart by cDNA microarray. Journal of Endocrinology 182 303-314. (doi:10.1677/joe.0. 1820303)

Degens H, Glide AJ, Lindhout M, Willemsen PH, van der Vusse GJ \& van Bilsen M 2003 Functional and metabolic adaptation of the heart to prolonged thyroid hormone treatment. American Journal of Physiology. Heart and Circulatory Physiology 284 H108-H115. (doi:10.1007/ s10741-008-9125-7)

Dillmann W 2010 Cardiac hypertrophy and thyroid hormone signaling. Heart Failure Reviews 15 125-132. (doi:10.1007/s10741-008-9125-7)

Drazner MH 2005 The transition from hypertrophy to failure: how certain are we? Circulation 112 936-938. (doi:10.1161/CIRCULATIONAHA 105.558734)

Fadel BM, Ellahham S, Ringel MD, Lindsay J, Wartofsky L \& Burman KD 2000 Hyperthyroid heart disease. Clinical Cardiology 23 402-408. (doi:10.1002/clc.4960230605)

Garcia JM 2010 Thyroid hormone and myocardial mitochondrial biogenesis. Vascular Pharmacology 52 120-130. (doi:10.1016/j.vph. 2009.10.008)

Garcia JM \& Goldenthal MJ 2002 Understanding the impact of mitochondrial defects in cardiovascular disease: a review. Journal of Cardiac Failure 8 347-361. (doi:10.1054/jcaf.2002.127774)

Ghosh G, De K, Maity S, Bandyopadhyay D, Bhattacharya S, Reiter RJ \& Bandyopadhyay A 2007 Melatonin protects against oxidative damage and restores expression of GLUT4 gene in the hyperthyroid rat heart. Journal of Pineal Research 42 71-82. (doi:10.1111/j.1600-079X.2006. 00386.x)

Goffart S, Kliest-Retzow JCV \& Wiesner RJ 2004 Regulation of mitochondrial proliferation in heart: power-plant failure contributes to cardiac failure in hypertrophy. Cardiovascular Research 64 198-207. (doi:10.1016/j.cardiores.2004.06.030)

Goglia F, Moreno M \& Lanni A 1999 Action of thyroid hormones at cellular level: the mitochondrial target. FEBS Letters 452 115-120. (doi:10.1016/ S0014-5793(99)00642-0)

Gustafsson AB \& Gottlieb RA 2008 Heart mitochondria: gates of life and death. Cardiovascular Research 77 334-343. (doi:10.1093/cvr/ cvm005)

Hunter JJ \& Chien KR 1999 Signaling pathways for cardiac hypertrophy and failure. New England Journal of Medicine 341 1276-1283. (doi:10.1056/NEJM199910213411706)

Huss JM \& Kelly DP 2004 Nuclear receptor signaling and cardiac energetics. Circulation Research 95 568-578. (doi:10.1161/01.RES.0000141774. 29937.e3)

Huss JM \& Kelly DP 2005 Mitochondrial energy metabolism in heart failure: a question of balance. Journal of Clinical Investigation $\mathbf{1 1 5}$ 547-555. (doi:10.1007/s10557-006-0643-z)

Hyyti OM \& Portman MA 2006 Molecular mechanisms of crosstalk between thyroid hormone and peroxisome proliferator activated receptors: focus on the heart. Cardiovascular Drugs and Therapeutics 20 463-469. (doi:10.1007/s10557-006-0643-z)

Ingwall JS 2009 Energy metabolism in heart failure and remodelling. Cardiovascular Research 81 412-419. (doi:10.1093/cvr/cvn301) 
Ingwall JS \& Weiss RG 2004 Is the failing heart energy starved? On using chemical energy to support cardiac function Circulation Research $\mathbf{9 5}$ 135-145. (doi:10.1161/01.RES.0000137170.41939.d9)

Jonkers IJ, de Man FH, van der Laarse A, Frolich M, Gevers Leuven JA, Kamper AM, Blauw GJ \& Smelt AH 2001 Bezafibrate reduces heart rate and blood pressure in patients with hypertriglyceridemia. Journal of Hypertension 19 749-755. (doi:10.1097/00004872-200104000-00012)

Kahaly GJ \& Dillmann WH 2005 Thyroid hormone action in the heart. Endocrine Reviews 26 704-728. (doi:10.1210/er.2003-0033)

Kenzel V, Soukup T, Okruhlikova L', Slezak J \& Tribulova N 2008 Thyroid hormones modulate occurrence and termination of ventricular fibrillation by both long-term and acute actions. Physiological Research 57(Suppl 2) S91-S96.

Kieck-Wilk B, Kieck AD, Olsazanecka A, Bodzioch M \& Kawecka-Jaszcz K 2005 The selected pathophysiological aspects of PPARs activation. Journal of Physiology and Pharmacology 56 149-162.

Klein I \& Ojamaa K 2001 Thyroid hormone and the cardiovascular system. New England Journal of Medicine $\mathbf{3 4 4}$ 501-509. (doi:10.1056/ NEJM200105103441901)

Lefebvre P, Chinetti G, Fruchart JC \& Staels B 2006 Sorting out the roles of PPAR $\alpha$ in energy metabolism and vascular homeostasis. Journal of Clinical Investigation 116 571-580. (doi:10.1172/JCI27989)

Lehman JJ \& Kelly DP 2002 Gene regulatory mechanisms governing energy metabolism during cardiac hypertrophic growth. Heart Failure Reviews 7 175-185. (doi:10.1023/A:1015332726303)

Lewis W, Haase CP, Raidel SM, Russ RB, Sutliff RL, Hoit BD \& Samarel AM 2001 Combined antiretroviral therapy causes cardiomyopathy and elevates plasma lactate in transgenic AIDS mice. Laboratory Investigation 81 1527-1536. (doi:10.1038/labinvest.3780366)

Liao R, Nascimben L, Friedrich J, Gwathmey JK \& Ingwall JS 1996 Decreased energy reserve in an animal model of dilated cardiomyopathy. Circulation Research 78 893-902. (doi:10.1161/01.RES.78. 5.893)

Luci S, Kluge H, Hirche F \& Eder K 2006 Clofibrate increases hepatic triiodothyronine $\left(\mathrm{T}_{3}\right)$ - and thyroxine $\left(\mathrm{T}_{4}\right)$-glucoronosyltransferase activities and lowers plasma $\mathrm{T}_{3}$ and $\mathrm{T}_{4}$ concentrations in pigs. Drug Metabolism and Disposition 34 1887-1892. (doi:10.1124/dmd.106. 011379)
Marín-García J, Goldenthala MJ \& Moe GW 2001 Abnormal cardiac and skeletal muscle mitochondrial function in pacing-induced cardiac failure. Cardiovascular Research 52 103-110. (doi:10.1016/S00086363(01)00368-6)

Pacher P, Nagayama T, Mukhopadhyay P, Batkai S \& Kass DA 2008 Measurement of cardiac function using pressure-volume conductance catheter technique in mice and rats. Nature Protocols 3 1422-1434. (doi:10.1038/nprot.2008.138)

Pinz I, Tian R, Belke D, Swanson E, Dillmann W \& Ingwall JS 2011 Compromised myocardial energetic in hypertrophied mouse hearts diminish the beneficial effect of overexpressing SERCA2A. Journal of Biological Chemistry 286 10163-10168. (doi:10.1074/jbc.M110.210757)

Rodriguez-Gomez I, Cruz A, Moreno JM, Soler A, Osuna A \& Vargas F 2008 Clofibrate prevents and reverses the hemodynamic manifestations of hyperthyroidism in rats. American Journal of Hypertension 21 341-347. (doi:10.1038/ajh.2007.58)

Sarma S, Ardehali H \& Gheorghiade M 2012 Enhancing the metabolic substrate: PPAR- $\alpha$ agonists in heart failure. Heart Failure Reviews $\mathbf{1 7}$ 35-43. (doi:10.1007/s10741-010-9208-0)

Shohet RV, Kisanuki YY, Zhao XS, Siddiquee Z \& Franco F 2004 Mice with cardiomyocyte specific disruption of endothelin-1 gene are resistant to hyperthyroid cardiac hypertrophy. PNAS 101 2088-2093. (doi:10.1073/pnas.0307159101)

Shoshan-Barmatz V, De Pinto V, Zweckstetter M, Raviv Z, Keinan N \& Arbel N 2010 VDAC, a multi-functional mitochondrial protein regulating cell life and death. Molecular Aspects of Medicine 31 227-285. (doi:10.1016/j.mam.2010.03.002)

Tsutsui H, Kinugawa S \& Matsushima S 2009 Mitochondrial oxidative stress and dysfunction in myocardial remodeling. Cardiovascular Research $\mathbf{8 1}$ 449-456. (doi:10.1093/cvr/cvn280)

Ventura-Clapier R, Garnier A \& Veksler V 2003 Energy metabolism in heart failure. Journal of Physiology 555 1-13. (doi:10.1113/jphysiol.2003. 055095)

Yen PM 2001 Physiological and molecular basis of thyroid hormone action. Physiological Reviews 81 1097-1130.

Zhang J, Liem DA, Mueller M, Wang Y, Zong C, Deng N, Vondriska TM, Korge P, Drews O, Maclellan WR et al. 2008 Altered proteome biology of cardiac mitochondria under stress conditions. Journal of Proteome Research 7 2204-2214. (doi:10.1021/pr070371f)

Received in final form 19 January 2013

Accepted 19 February 2013

Accepted Preprint published online 19 February 2013
(C) 2013 Society for Endocrinology Printed in Great Britain 